\title{
Gestão do Sofrimento e Luta pela Moradia por Famílias Trabalhadoras
}

\author{
Priscila Tavares dos Santos ${ }^{1}$ \\ ${ }^{1}$ Maxwell School of Citizenship \& Public Affairs, Syracuse University, Syracuse, \\ New York, Estados Unidos
}

\begin{abstract}
Resumo
Proponho neste artigo refletir sobre as condições de acesso aos direitos sociais dos moradores do Predinho, moradia popular constituída nas instalações do antigo Hotel Bandeirantes, na região central do Rio de Janeiro. A adoção da perspectiva processual e a análise interpretativa dos dados permitiram compreender as diferentes formas de gestão e os agenciamentos morais que buscam legitimar os processos decisórios que correspondem a essa forma de viver e habitar a cidade. Valorizo a compreensão simbólica do direito à moradia e os aspectos simbólicos, afetivos e não institucionais que compõem relações de poder entre moradores e representantes do Estado. As condições de possibilidade de reprodução social dessas famílias evidenciam a situação de vulnerabilidade social e revelam que o Estado não garante direitos, mas condiciona o mecanismo perverso de resistência ao tempo pela apropriação de escassos recursos individuais complementados por redes de relações intrafamiliares e intervencionistas.
\end{abstract}

Palavras-chave: Luta por Moradia. Direitos Sociais. Gestão Autônoma. Habitação Popular.

\section{Management of Suffering and Struggle for Housing by Working Families}

\begin{abstract}
I propose to reflect on the conditions of access to the social rights of the residents of Predinho, a popular dwelling built on the premises of the former Hotel Bandeirantes, in the central region of Rio de Janeiro. The adoption of the procedural perspective and interpretative analysis of the data allowed us to understand the different forms of management and moral agencies that seek to legitimize the decision-making processes that correspond to this way of living and inhabiting the city. I value the symbolic understanding of the right to housing and the symbolic, affective and non-institutional aspects that make up power relations between residents and representatives of the State. The conditions for the possibility of social reproduction of these families show the situation of social vulnerability and reveal that the State does not guarantee rights, but conditions the perverse mechanism of resistance to time by the appropriation of scarce individual resources complemented by networks of intrafamily and interventionist relationships.
\end{abstract}

Keywords: Struggle for Housing. Social Rights. Autonomous Management. Popular Housing. 


\section{Introdução}

$\mathrm{N}$ este texto, apresento algumas reflexões tecidas no âmbito do Projeto "Lutas pela Moradia no Centro da Cidade" (em andamento desde 2016), que têm como objetivo a compreensão dos esforços empreendidos por conjunto de famílias na demanda pela moradia na região portuária e suas adjacências na cidade do Rio de Janeiro. Por esta pesquisa, objetiva-se compreender os esforços empreendidos pelos moradores mobilizados e beneficiários de políticas habitacionais pela permanência em um espaço imbricado por competições pelo uso e pela apropriação do território, foco de projeto de "revitalização" subsidiado pelo Estado, a exemplo de outras regiões metropolitanas do chamado Terceiro Mundo que sofreram com os efeitos da transformação de áreas de baixo valor das propriedades em áreas de alto valor imobiliário. No âmbito do projeto, foram valorizadas diferentes experiências de mobilização comunitária sob a perspectiva dos valores das famílias trabalhadoras na luta pelo acesso ao direito à moradia.

Adoto, para tanto, investimentos dos moradores do antigo Hotel Bandeirantes, experiência autônoma de mobilização familiar para ocuparem e permanecerem em imóveis desocupados e em situação de litígio judicial. Como almejo destacar, a ocupação do Predinho corresponde a uma forma de resistência ao projeto desenvolvimentista que levou ao deslocamento de famílias de baixa renda da região central para bairros de periferia da cidade que exacerbaram as condições de vulnerabilidade em que vivem essas famílias, que, durante o período de desenvolvimento do trabalho de campo etnográfico, reivindicavam o acesso a direitos fundamentais, como o de moradia, saúde, educação, assistência social, além do acesso aos recursos disponibilizados nos centros urbanos, como luz, água, transporte, eventos culturais, e que inclusive operam como espaços de trabalho informal nesse contexto fundamental à subsistência desses interlocutores.

Considerando diferentes investimentos e abordagens teórico-metodológicas, priorizei a compreensão da construção de empreendimentos habitacionais sobre a estrutura das relações sociais dos moradores do antigo Hotel, destacando diferentes arranjos espaciais e seus efeitos sobre os projetos de reprodução sociall das famílias residentes no chamado Predinho (alcunha atribuída pelos moradores ao projeto de moradia popular que construíram nas dependências do desativado Hotel Bandeirantes). O trabalho

Como projetos de reprodução social elaborados pelas famílias de moradores do Predinho, valorizo a incorporação de recursos prioritariamente utilizados para a gestão produtiva do espaço de moradia, segundo sistema de valores localmente construído e reconhecido (BOURDIEU, 2011). Em análise junto aos horticultores em Teresópolis, Santos (2015) destacou a diversidade de possibilidades de constituição de projetos de reprodução social, muitas vezes, a partir de investimentos para obtenção de recursos situacionais como necessários para a garantia e a manutenção de uma determinada posição social. 
de campo etnográfico priorizou ferramentas como a observação direta e a observação participante, além de entrevistas e conversas informais com os moradores do Predinho nas unidades residenciais e nos espaços de utilização coletiva, como corredores e áreas de serviço. Em muitos desses encontros, as entrevistas não foram gravadas em respeito aos entrevistados e pelo risco imposto aos moradores diante das temáticas abordadas nos encontros. Com o intuito de complementar algumas lacunas para compreensão do processo de ocupação e dos significados atribuídos pelos moradores ao Predinho, valeu-se de dados arquivísticos e de publicações em jornais, além de dados oficiais compilados pelo acesso à parte do processo judicial de reconhecimento de usucapião coletivo do imóvel. As entrevistas foram realizadas sem utilização do gravador e, portanto, correspondem a anotações no diário de campo e aos dados obtidos pela observação participante.

A perspectiva processual que adoto na compreensão dos dados permite valorizar as diferentes formas de gestão e o uso do espaço de moradia e dos princípios que orientam a constituição de redes de relações de solidariedade e ajuda mútua entre essas famílias. A realização do trabalho de campo esteve orientada conforme as técnicas e ferramentas consideradas por Malinowski (1998), especialmente o exercício da observação participante em encontros formais (nas reuniões de moradores) e informais do grupo (festividades e outros encontros). O olhar atento aos engajamentos e às situações de participação coletiva, às condições de moradia, às circulações das famílias para constituição de alianças e às redes de relações viabilizadoras do projeto de permanência no centro da cidade foram fundamentais para a obtenção dos dados e a compreensão dos princípios que orientam as ações desses moradores em situações de tomada de decisão.

Privilegiei ainda a realização de entrevistas e conversas informais, além da observação participante nas unidades residenciais e espaços de utilização coletiva, como corredores e áreas de serviço. A experiência de pesquisa por mim valorizada é composta de um grupo de 41 famílias que, sob a liderança majoritária de mulheres, ocuparam esse espaço por eles reconhecido como Predinho. Nesse sentido, busco demonstrar ainda o quão produtivo é o trabalho das mulheres, além do trabalho gratuito realizado no espaço doméstico.

Por esses investimentos, busquei trazer à tona fatores que influenciaram no processo de organização coletiva dessas famílias na luta pela moradia e na gestão do sofrimento imposto como realidade social e política a essas famílias (FASSIN, 1999). As formas de mobilização coletiva dessas famílias com as quais pude ter contato (desde 2016) correspondem a estratégias locais para enfrentamento da situação de exclusão dessas famílias do acesso a recursos materiais e da negação do acesso pelo Estado do direito à moradia.

\section{O Hotel Bandeirantes e a Construção Social do Predinho}

O Hotel Bandeirantes foi construído durante meados da década de 1970 e correspondeu a um projeto desenvolvimentista do Rio de Janeiro, em especial para atendimento ao mercado consumidor associado ao turismo em expansão, mediante a oferta de instalações luxuosas de suas dependências. 
Refletindo com os interlocutores sobre a história do espaço por eles ocupado e diante das dificuldades encontradas para acesso a trabalhos acadêmicos que tivessem investido na compreensão dos processos de construção do sistema hoteleiro no estado, busquei outra fonte de dados ${ }^{2} \operatorname{com}$ a qual pudesse dialogar e que ajudasse a elucidar o que os interlocutores mencionavam. Por esse investimento metodológico, pude chegar à compreensão de alguns dos princípios ordenadores de uso daquele espaço e do processo de urbanização que afastou da região central a classe de trabalhadores que, na contracorrente da política pública de desenvolvimento, integraram-se à cidade a partir de outras estratégias, quase sempre colocadas em prática a partir de recursos próprios e em condições de relativa precarização, como é o caso das favelas cariocas (LEEDS; LEEDS, 2015). Os textos jornalísticos aos quais se teve acesso anunciavam, durante a década de 1980, formas de consumo dos diferentes espaços do hotel pela elite empresarial e pela classe média carioca. Especialmente na unidade de Copacabana, eram recorrentes as publicações de convites para eventos sociais e workshops sobre temáticas diversas (com destaque para aqueles voltados para o desenvolvimento de aptidões humanas). No entanto, concomitantemente eram noticiados acontecimentos que podem ser considerados preponderantes para o afastamento da elite consumidora das dependências do hotel, como aqueles decorrentes de uma possível associação com eventos criminosos no final da década de 1990. Após esses episódios considerados de crise e de colocação em suspeição da capacidade de atendimento às exigências de oferta de instalações adequadas aos hóspedes da classe média, o Hotel Bandeirantes foi interditado em 1988 e, decorrido um ano após o encerramento das atividades, os gestores das redes Othon e Bandeirantes renovaram o contrato de arrendamento, entretanto deixando de lado a unidade Centro do Rio (JORNAL DO BRASIL, 1988; TRIBUNA DA IMPRENSA, 1999).

Foi então que, em 2003, um conjunto formado por famílias de trabalhadores na região do entorno da Central do Brasil (especialmente mobilizados pelo desemprego e pela violência no Morro da Providência) ocuparam o imóvel. A arquitetura do prédio se assemelha à estrutura de hotéis de meados do século XX: escadas em mármore, corredores estreitos e com pouca iluminação que convergem em quartos pequenos (com aproximadamente $15 \mathrm{~m}^{2}$ e uma área que funciona como um pátio interno ${ }^{3}$. O grupo era constituído principalmente por mulheres com faixa etária entre 30 e 50 anos, quase todas com filhos dependentes de cuidado intensivo (crianças na faixa entre 2 e 7 anos de idade), sem vínculo formal de trabalho, com moradia precária. Em sua maioria, são originários de bairros próximos (Centro e Tijuca) e da Zona Norte (Nova Iguaçu e Duque de Caxias), e alguns são provenientes de estados do Nordeste do país (Rio Grande do Norte e Ceará) que, segundo relatos, vieram para o Rio estimulados pelo desejo de realização do sonho da casa própria e do acesso ao mercado de trabalho pelo vínculo formal em expansão pela política de urbanização e de desenvolvimento industrial na década de 1980, conforme mencionou uma entrevistada.

\footnotetext{
Foram utilizados textos jornalísticos a partir de consulta a Hemeroteca Digital (no período de 1980 a meados de 1990) que faziam referências aos usos diversos das dependências do Hotel.

3 Essa arquitetura predial também foi relatada por Paterniani (2013) no trabalho etnográfico realizado na ocupação Mauá, na região central da cidade de São Paulo.
} 
Esse projeto de melhoria de vida corresponde a um conjunto de investimentos autônomos operacionalizados a partir de deslocamentos de famílias, muitas vezes, da área urbana para a periferia das cidades. A autonomia como princípio norteador das ações dos moradores do Predinho se contrapõem à condição de subordinação a projetos desenvolvimentistas com a alcunha de revitalização de espaços já ocupados (como é o caso da região central do Rio de Janeiro) e, por outro lado, de valorização de estratégias diversificadas na elaboração de projetos de reprodução social, tal como destacou Bourdieu (2011).

Como afirmou Moraes (2020), a permanência dessa parcela da população - seja a partir de ocupações em espaços baldios, seja a partir da ocupação de prédios públicos e/ ou privados - nesses espaços, à despeito da política habitacional, aponta para formas de enfrentamento que evidenciam novas experimentações de "voltar à vida" (MORAES, 2020, p. 20). De acordo com o autor:

Entre empregos e desempregos, baixas expectativas em relação a qualquer estabilidade relacionada ao trabalho, aos pobres na cidade exige-se, cada vez mais, a disponibilidade total - seja para acessar uma política pública ou para candidatar-se à uma vaga de emprego subalternizado e sem garantias [...]. (MORAES, 2020, p. 20)

No caso em tela, o movimento observado é o inverso: as famílias migraram de zonas de periferia e de "favelas" para ocuparem o centro urbano. Esse sentido do deslocamento pode estar associado ao que Lefebvre (2001) considerou a partir das projeções da sociedade sobre um local. Nesse sentido, a cidade em si agrega as diferenças entre as cidades, porque é constituída "pela pluralidade, pela coexistência e simultaneidade" de padrões e de maneiras de viver a vida urbana (LEFEBVRE, 2001, p. 63).

O valor do trabalho, mesmo que sob afiliação ao mercado informal, é muito mais do que o "instrumento da sobrevivência material" dessas famílias, mas constitui o "substrato da identidade", da "autonomia moral" (SARTI, 1996, p. 66), que, no caso do Predinho, se expressa a partir da identidade das mulheres. Segundo mencionaram em situação de entrevista, identificam-se como diaristas, auxiliares de pedreiro, camelôs, vendedoras ambulantes, formas de inserção produtiva que têm viabilizado o projeto de desenvolvimento urbano, desempenhando papel central no coração da sociedade carioca para colocação em prática do projeto de revitalização da zona portuária, como "força de trabalho dócil e barata" (FASSIN, 1999, p. 184).

\section{A Construção da Moradia Digna}

As moradias correspondem a uma forma de resistência a esse projeto desenvolvimentista que levou ao deslocamento de centenas de famílias de baixa renda para a periferia da cidade. A luta pela moradia, ocupação e pela posse dos quartos do antigo Hotel Bandeirantes e o reconhecimento do uso social de suas instalações como unidades residenciais independentes se potencializam pela instalação de processo judicial, em 2007, sob mediação da Defensoria Pública estadual. Por essa demanda, os moradores 
pleiteiam pelo reconhecimento do trabalho que desenvolveram na transformação ${ }^{4}$ do espaço e aguardam pelo documento de concessão da usucapião coletivo do imóvel. A luta pela moradia passou então a ganhar visibilidade quando incorporou dinâmicas de mobilização nesses espaços governamentais que estão associados a demonstrações públicas da capacidade mobilizadora dessas famílias, como também foi demonstrado por Moraes (2020), que tem se dedicado à análise dos sentidos das lutas sociais e às relações entre formas de vida em acampamentos em terrenos baldios na cidade de São Paulo.

As tratativas para encaminhamento da demanda do direito à moradia se maximizam na esfera cotidiana dessas famílias de moradores que, com recursos próprios e como expressão de um desejo coletivo autônomo, realizam inúmeros investimentos na melhoria do espaço com o objetivo de criar, como expressão local, uma moradia digna que, segundo os interlocutores, pode ser definida como o acesso à casa e também a recursos e serviços públicos disponíveis em espaços centrais da cidade. Cabe aqui destacar que a categoria também foi valorizada por Paterniani (2013) em investimento para compreensão da extensão dos deslocamentos da relação entre os movimentos de moradia e os representantes da administração municipal em São Paulo. Priorizando como interlocutores militantes do movimento de luta por moradia e moradores da ocupação Mauá (situada na região central da capital paulista), a autora aponta os investimentos realizados pelo movimento de moradia na luta pelo acesso ao "direito à moradia digna para pessoas de baixa renda", caracterizadas, nesse contexto, por famílias cuja renda mensal é entre zero e três salários mínimos (PATERNIANI, 2013, p. 3).

O uso desse termo pelos moradores do Predinho é recorrente e corresponde ao projeto de moradia que, tal como analisado por Sarti (1996) e Domingues (2011), aponta para expectativas de atendimento a condições por eles consideradas essenciais para residência, especialmente no que tange à infraestrutura e à oferta de recursos públicos (como luz e água encanada). No entanto, a situação de invisibilidade dos ocupantes (termo designativo da situação de vulnerabilidade pela ilegalidade da condição de moradia atribuída) do Predinho, espaço ainda não contemplado pelo projeto de reconstrução da zona central da cidade como área de interesse social (como se pode observar pelos esqueletos de prédios comerciais e públicos que teimam em sobreviver aos efeitos do tempo, à falta de investimento e de manutenção nos arredores do imóvel ocupado) constitui esse cenário de negligência do poder público no Rio de Janeiro, tal como percebido pelos atores sociais. Assim, na condição de excluídos do acesso ao direito à moradia pela ineficiência do estado na tramitação do processo de demanda coletiva de usucapião do imóvel, os moradores do Predinho têm realizado uma série de investimentos para minimizarem os efeitos do exercício precário à moradia que se distingue da experiência de vida na favela.

Segundo relatos, o período de permanência dos moradores no prédio tem se caracterizado por uma ocupação contínua e pacífica e, diante da delonga processual quanto ao reconhecimento por parte do Estado do direito à moradia desses sujeitos, as condições de possibilidade de reprodução social dessas famílias que vivem em situação de vulnerabilidade social estão restritas à capacidade individual de se constituírem como sofredores e, portanto, merecedores da dádiva de vizinhos e das relações com comerciantes

4 Adoto o uso do termo "transformação" como forma de distinção proposta por Balandier ( 1969) para analisar movimentos que equivalem a uma operação da própria estrutura que configura o sistema. 
locais, além de redes de relações intrafamiliares e intervicinais. A requalificação da condição de pobreza produz, como apontou Neves (2011), efeitos classificatórios a partir da noção de merecimento como valor orientador das ações de construção do espaço de moradia familiar. A autora, para compreender os efeitos dos extremos índices de desigualdade socioeconômicas e os modos de enfrentamento político daqueles que vivem em situações miseráveis de vida, investiu no estudo da constituição dessas famílias (NEVES, 2011). Por esse exercício, ela destacou a centralidade da posição da mulher, mãe ou esposa na elaboração de projetos de reprodução social'5.

Os investimentos realizados pelos moradores na transformação das instalações do que até meados da década de 1990 integrava a rede de hotéis de luxo na cidade do Rio de Janeiro não devem ser compreendidos apenas sob o prisma da forma de uso do espaço, mas também como ação política intencional de disputa pelo controle do uso de recursos até então privilegiados de consumo da classe média (LEEDS; LEEDS, 2015).

Na tentativa de reconstruir com os interlocutores a história social do prédio, o que chamou a atenção foram as condições de completo abandono e de destruição das instalações do que há cerca de uma década correspondeu ao centro social e cultural do Rio de Janeiro. Esse abandono também se expressa no processo judicial em que o então proprietário do imóvel, tal como inscrito no Imposto Territorial Urbano, não se apresentou ao litígio. Descreveram os moradores as ações em mutirões para retirada dos móveis degradados pelo tempo e para realocar os resíduos depositados por moradores de rua que, recorrentemente, utilizavam os corredores do antigo hotel como abrigo nos dias de chuva e frio. Esses episódios de mobilização coletiva agregadora eram organizados para viabilizar a entrada no prédio - fase denominada pelos moradores como invasão -, e para assegurar condições mínimas de permanência, etapa por eles identificada como ocupação. Moraes (2020, p. 20), ao analisar as experiências da vida-ocupação experimentadas pelos sem-teto na região central de São Paulo, destacou que esse período de luta para acesso à ocupação se distingue da luta como "tomada de consciência" e se aproxima de uma luta enquanto movimento em busca dos sentidos de habitar que mobiliza uma "nova trama relacional, imprevisível e provisória".

Durante essa etapa, a luta pela posse do prédio exigia dos interlocutores a manutenção do estado de vigília constante, especialmente diante dos inúmeros ataques de "famílias que também não tinham onde morar" e do enfrentamento da força policial que cotidianamente fazia visitas ao prédio, relatou Lucia (61 anos). Ela comentou ainda:

Antes aqui, eu tinha muito medo. A gente sentia muito medo quando os policiais chegavam aqui fora de hora e saíam assim esculachando a gente. Eles não batiam na porta da gente. Às vezes, a gente estava dormindo, todo mundo deitado, e eles vinham e arrombavam a porta da gente. Por que não batiam? Eles queriam mesmo humilhar a gente. Não respeitavam o horário da gente descansar! Eles sabiam que a gente aqui era trabalhador. Os policiais sabiam quem era morador e quem queria bagunça. (Lucia, entrevista realizada em junho de 2019)

\footnotetext{
5 Inúmeros foram os investimentos realizados por Neves para compreensão dos fatores que influenciam na constituição da condição de existência de famílias em situação de vulnerabilidade social, dos quais destaco: As idosas provedoras e o enraizamento familiar, incluída na obra organizada intitulada Etnografias da Participação, pela editora Edunisc, em 2006, p. 359-379; além de A trajetória da população de rua e suas estratégias de sobrevivência, apresentada no Io Seminário de População de Rua, em 1995, em São Paulo, e da População de Rua Brasil e Canadá, São Paulo, pela Hucitec, em 1995, p. 61-70.
} 
Pires (2011), tendo se dedicado à compreensão dessa categoria esculacho, qualificado por comerciantes da região da Central do Brasil que sofriam com a retenção das mercadorias por policiais e agentes da vigilância, chamou atenção para a violência tanto física quanto moral da ação do esculacho pelos policiais. A descrição desses atos em muito se aproxima da experiência dos moradores do Predinho que, como demonstrou o autor, ressaltaram a humilhação e o constrangimento como sentimentos que marcavam a trajetória de vida do sujeito (PIRES, 2011).

Nesse período inicial da ocupação do imóvel, o prédio encontrava-se "dominado pelo lixo, havia lama pelos corredores" do primeiro e segundo andares do prédio, as louças sanitárias, lâmpadas, fiações e encanamentos foram encontrados em estado de completa degradação e "nada pôde ser aproveitado", destacou Lucia. Seu esposo, João (62 anos) comentou o processo aleatório de distribuição dos apartamentos aos recém-chegados:

Aqui era assim: chegou, se não tinha nada, podia pegar que não tinha dono. Eu cheguei aqui, e o apartamento aqui do segundo andar estava vazio. Não tinha colchão de ninguém lá. Não tinha roupa. Nada. Eu entrei e botei minhas coisas lá. Enquanto eu trabalhava, Lucia ficava com a menina. Tinha que deixar alguma coisa, senão alguém vinha e pegava mesmo. Deixava assim algum pertence: colchão, uma televisão, o que tivesse. (João, entrevistado em junho de 2019)

Esse período de investimento autônomo dos sujeitos da pesquisa para ressignificarem aquele hotel não correspondeu a um processo pacífico, mas pode ser compreendido como uma ação política intencional de ocupar um espaço que antes não estava disponível em termos de possibilidade de moradia temporária, mesmo que na condição de hóspedes, segundo relataram os interlocutores. Esse processo de transformação do imóvel abandonado em moradia familiar correspondeu a projeto autônomo das famílias. Relatou Lucia:

Eu sempre fui voluntária aqui. Nunca fui de cobrar nada a ninguém não. Eu cuidava do caderninho, anotava tudo, cuidava do caixa do prédio. Ia organizando tudo. Eu fazia o registro com despesas de compra de material de limpeza. Hoje, o que a Antônia faz aí, de ter que comprar o cloro e o sabão do próprio bolso. Não existia. Ia de porta em porta vendo quem não tinha pago. Não deixava atrasar o salário da limpeza. Era tudo direitinho. A gente chegou até botar câmera no prédio! Também consertamos o telhado que, na época, estava muito ruim, desabando mesmo, sabe? Só que com o tempo, não fomos mais tendo condições de pagar a taxa. Hoje, uns pagam, outros não. A maioria não paga. Sem trabalho, pagar como? (Lucia, entrevista realizada em junho de 2019)

O tempo de investimento e o grau de comprometimento dos moradores na viabilização do projeto de moradia são fatores considerados na concessão de imóveis avaliados como melhores (em relação à luminosidade, à proximidade com a escadas de acesso - tanto no primeiro quanto no segundo andar e tamanho do apartamento). Nesse sentido, os investimentos para concretizar a moradia nesse espaço distinguem-se ao longo desse processo de transformação de um espaço abandonado e impessoal em ambiente habitável e com condições adequadas de residência relativamente estável.

Na superação dos entraves para acesso ao prédio, foi fundamental o papel de liderança desempenhado pelas mulheres. A potencialidade das mulheres na constituição de espaços de mobilização é concebida como princípio orientador das práticas de luta pelo acesso à moradia e que, no caso do Predinho, tem assegurado às mulheres e aos demais moradores acesso a um conjunto de recursos escassos pela confluência de interesses 
situacionalmente valorizados. Em contraste ao que demonstrou Furno (2015), as diferenças de gênero nesse contexto do Predinho não são responsáveis pela diferenciação de papéis sociais específicos.

A residência, mesmo que precária em termos de recursos materiais, é alternativa valorizada pelos moradores diante da possibilidade de acesso a recursos que, comparativamente à moradia na favela, estão disponíveis, como é o caso de luz elétrica, suprimento de água, serviço de esgoto.

Os princípios que orientam esse sistema de classificação local dos moradores permitem entrever que as fronteiras são fluidas, porque as relações que as constituem são operacionalizadas segundo os diferentes estágios de desenvolvimento da unidade doméstica e da composição familiar; bem como os níveis diferenciados de adesão aos projetos comuns privilegiados a cada contexto pelos interlocutores da pesquisa, inclusive adesão a projetos político-partidários. Mencionou Maria (58 anos)

Nós somos ocupantes, para o governador, né. Mas nós aqui somos moradores. Estamos aqui há muito tempo, e eles (os representantes do governo) não dão apoio nenhum para a gente. Como você pode votar em um candidato que é contra a gente?! Ele é contra as ocupações e vai tirar a gente daqui?! Eu aqui coloquei adesivo na minha porta! Coloquei mesmo! Como você vota em alguém deste partido aí? (Maria, entrevistada em maio de 2019)

No relato acima, fica evidente o modo como os moradores do Predinho percebem a condição de excluídos como um fenômeno relacionado a políticas estatais. Essa concepção se aproxima das reflexões de Fassin (1999) sobre a condição de homens sem direitos e os investimentos que grupos de indígenas e imigrantes africanos empreendem no sentido de terem acesso a direitos básicos.

\section{A Gestão do Sofrimento e a Constituição do Merecedor}

No caso dos moradores, o papel de liderança desempenhado pelas mulheres produz efeitos classificatórios a partir da noção de merecimento como noção associada a investimentos individuais na luta pela construção do espaço coletivo de moradia, tal como uma confluência de forças, que permite ao ocupante tornar-se merecedor de um apartamento (e, portanto, ter os atributos sociais igualmente reconhecidos) e, por consequência, ser reconhecido como um morador. Os atributos sociais que as lideranças locais têm destacado evidenciam a experiência do sofrimento, de exploração da força de trabalho. Ser merecedor é ter experimentado uma vida de instabilidade, por vezes sob ameaças de violência.

A lógica do merecimento nesse contexto se aproxima da concepção weberiana do trabalho, da valorização do esforço que precisa estar associado ao reconhecimento público para viabilizar o acesso a recursos (WEBER, 2001). O merecimento está marcado pela trajetória de necessidade não apenas de moradia, mas como símbolo moral de recompensa pela condição de abandono do Estado e também da ausência do companheiro. Por outro lado, ter necessidade está associado à abertura de um outro universo de relações sociais marcadas pela solidariedade e camaradagem, especialmente entre mulheres, que organizavam suas ações conforme a lógica do ganha quem precisa. 
No caso do sofrimento provocado pela exclusão a recursos materiais, uma moradora descreveu em situação de entrevista as diversas vezes em que precisou "pedir ajuda a comerciantes" do entorno do prédio para garantir o "sustento do filho", relatou Ana (40 anos). Distinguem-se duas ocasiões de favorecimento do morador como merecedor das benesses: ter necessidade e precisar. A necessidade está associada ao reconhecimento público da condição de precariedade e, por outro lado, precisar é ato individual e demanda por parte do sujeito a capacidade de articular redes ou de se inserir em redes de acesso a recursos que estejam disponíveis em momentos pontuais de escassez. O reconhecimento pelo outro da condição de necessitado não garante o atendimento à demanda, porque depende da constituição de um acúmulo de recursos que possam ser distribuídos ou mesmo realocados. Portanto, ganhar e pedir são ações comuns aos moradores do prédio, no entanto, o ato de ganhar demanda reconhecimento como alguém que merece ajuda; por outro lado, quem pede não foi reconhecido como merecedor, mas tem a possibilidade maior de ser atendido em seu pedido, especialmente se se reconstitui na condição de humilde. "Para ganhar o que pede, é preciso ter humildade", afirmou Ana.

A gente aqui nunca passou fome, fome de comida, a gente não passa. Nós temos necessidade de comprar uma coisa ou outra. Às vezes, a gente quer comprar uma blusinha, não tem dinheiro. A gente quer comprar uma coisa assim e não tem. Mas comida sempre tem. Então, fome a gente não passa. E é isso que a gente precisa. Quando precisa de uma comida, vai lá e pede. (Lúcia, entrevistada em agosto de 2018)

Lucia descreveu ainda as redes de relações de atendimento aos casos de urgência: "eles aqui são minha família, aqui eu me sinto em família. Se eu preciso de qualquer coisa, eu vou ali na fulana, vou na beltrana e peço". Como se pode compreender, as condições de possibilidade de acesso a recursos diversos pelas famílias de moradores, quase sempre marcadas pela escassez, contribuem na construção de um sistema de classificação que está pautado em princípios morais que tangenciam a luta pela moradia e que varia segundo a capacidade de gestão da precariedade, mormente pela articulação de redes de acesso a recursos.

Maria, moradora do prédio há 15 anos, reside em apartamento ampliado (pela incorporação de um quarto situado à direita) com dois filhos solteiros (João, 14 anos, estudante do ensino fundamental; e Pedro, 18 anos, estudante do ensino médio). A filha Ana, 25 anos, administradora, recentemente foi beneficiada com apartamento (mediante transferência de uma das moradoras que, há cerca de cinco meses, desistiu do projeto de residência no Predinho). Há cerca de dois anos, vive em união estável e fixou residência em um quarto ofertado na casa da sogra, enquanto realiza melhorias no apartamento para o qual pretende se mudar com Hugo (27 anos) e o filho Junior ( 1 ano).

A entrevistada se identifica e assim também é reconhecida pelos demais residentes como madrinha das crianças do Predinho e afirmou que "desde sua chegada, ainda no período da ocupação, ajuda a cuidar das crianças". O cuidado com as crianças se manifesta desde a oferta de alimentação em diferentes períodos do dia, mas também no asseio à saúde (dando banho e arrumando cabelo e roupas), como também está disponível para levá-las e buscá-las na escola, principalmente nos períodos em que os pais constituem vínculos de trabalho, mesmo que temporários.

Em situação de entrevista, pode-se observar as inúmeras vezes em que as crianças entram em seu apartamento "sempre de portas abertas", como reconheceu que faz questão de 
manter. A recepção em seu apartamento de boa parte das 20 crianças e adolescentes que residem no Predinho "sempre com carinho e muito amor", por vezes, é também acompanhada de advertências em casos de observação de desrespeito às regras do que considera como de "bom comportamento: jogar lixo pelos corredores do prédio, danificar as paredes e janelas, jogar bola nos corredores e fazer barulho durante o período da noite", avaliou Maria. O papel desempenhado pela entrevistada no cuidado com as crianças do prédio é fundamental para viabilizar que as mães possam buscar trabalho remunerado e terem acesso a recursos, mesmo que escassos, pelo baixo nível de formação profissional.

Outro caso de moradora que compartilha com Maria o desempenho do papel de apadrinhamento é Lúcia. A unidade residencial desta entrevistada é composta de seu esposo, Roberto ( 55 anos, desempregado) e de um casal de filhos: Julia (9 anos) e André ( 14 anos), ambos estudantes do ensino fundamental em escola filantrópica no Centro do Rio, mediante obtenção de bolsa de estudos. O casal teve uma filha que faleceu aos 5 anos de idade com leucemia e, nesse período, ainda não residiam no Predinho.

A chegada ao prédio pelo casal, em 2004, foi provocada pela impossibilidade de continuar o pagamento do aluguel do imóvel que residiam no Morro da Providência. Lúcia foi demitida da farmácia que trabalhava, e Roberto, após demissão da padaria, firmou vínculo informal como trabalhador de lanchonete na Central do Brasil. O rompimento do vínculo formal de trabalho inviabilizou a renovação do contrato de locação do imóvel e, mesmo rejeitando o projeto como ocupante, não encontraram à época outra alternativa de residência.

O casal, nesse período, passou a residir em um dos quartos do antigo hotel e trouxe a sobrinha de Lúcia (residente em bairro de periferia em Natal/RN), uma adolescente com 12 anos de idade. Segundo comentou, a sobrinha sofria maus-tratos e havia fugido de casa, passando a morar na casa de amigos. Ainda quando estudante do ensino médio, a sobrinha Aline teve um relacionamento amoroso com um dos moradores do Predinho e engravidou de uma menina. O rapaz, usuário de drogas, fugiu do prédio, deixando para trás a sua sobrinha e a filha recém-nascida (Juliana).

Além da adoção informal de Juliana, Lúcia também é responsável direta por André, filho da antiga vizinha Mariana (atualmente apenas sua mãe, Dona Regina, permanece no Predinho). Esclareceu: "André dorme aqui comigo, ele não fica com a avó dele. Ele fica comigo que sou a mãe, eu que cuido dele...". André tem acesso aos mesmos recursos que sua sobrinha-neta Juliana: estudam na mesma escola, no entanto, além da aula de luta na Vila, realiza curso preparatório para acesso ao Colégio Militar. O cursinho é particular, mas obteve bolsa de $80 \%$. Os recursos financeiros para pagamento da mensalidade são obtidos pela comercialização, em seu apartamento, de doces e guloseimas às crianças residentes do Predinho e àquelas que esporadicamente vêm visitar familiares.

Assim, para contemplar a diferenciação de condições de vida quanto aos espaços de habitação e de acesso a recursos, Neves (2014) destacou o papel das mulheres na construção de redes de integração. Pelo investimento etnográfico junto às mulheres de Santarém (AM), ele chamou atenção para o intercruzamento entre trabalho e gênero, vida familiar (doméstica e profissional) e relações vicinais e de parentesco. A construção das redes de solidariedade e de reciprocidade correspondem a " [...] modos de inserção em planos de ação coletiva ou de construção de quadros institucionais de proximidade 
[...]" (NEVES, 2014, p. 21), tanto no caso do papel de liderança desempenhado pelas mulheres em Santarém quanto aquelas que constituem uma das situações etnográficas priorizadas neste texto, em especial as mulheres do Predinho. A presença de mulheres, mães e esposas em ambas as situações etnográficas evidencia modos de viver/sobreviver e de compensação de limites impostos pela situação de vulnerabilidade social.

\section{Considerações Finais}

O paradoxo da figura do homem sem direitos, segundo considerou Fassin (1999), coloca em evidência, no caso do Predinho, investimentos coletivos autônomos mobilizados pelos moradores para viabilizarem o acesso ao direito à moradia e a recursos materiais por eles considerados essenciais no projeto de constituição da moradia digna, termo local que se contrapõe aos modelos de "cidade do progresso" e aos arranjos precários que impõem o ritmo desenfreado de novas formas de metropolização. O modelo imposto de constituição de "cidade do progresso" evidencia arranjos precários para pensar a desigualdade social, bem como os limites no acesso a recursos e serviços públicos pela população residente de baixa renda que reivindica a permanência nesses espaços.

Os inúmeros investimentos realizados pelos interlocutores para obtenção de recursos situacionalmente disponíveis e valorizados como fundamentais para assegurar a reprodução física e social apontam para a diversidade de projetos de reprodução social. Atenta às narrativas, pude compreender que as famílias do Predinho não projetam para si posições considerando apenas a relativa facilidade quanto ao acesso a recursos internos ao grupo familiar. Atividades produtivas marcadas pelo trabalho informal, como camelôs, cuidadoras de crianças, faxineiras, vendedores ambulantes em períodos de feriados prolongados (como o do Carnaval), apontam para um amplo espectro de ação e de quadro de alternativas em que os fatores que integram universos sociais mais amplos são relevantes para sua colocação em prática. Os fluxos de ações na constituição de redes de solidariedade e de afeto que busquei demonstrar neste texto só foram possíveis porque vali-me de perspectiva processualista e de análise interpretativa para apreensão de dados.

As famílias de moradores do Predinho, há cerca de 17 anos, lutam cotidianamente para serem reconhecidos como merecedores do direito à moradia. Ao longo desses anos, privados do acesso legal à casa, são também privados de um espaço no mundo social. Como tentei demonstrar, a condição de vulnerabilidade dessas famílias faz com que esses moradores sejam transformados em presas fáceis desse sistema de dominação e de exploração que se materializa nos centros urbanos no país (LEFEBVRE, 2001).

Como forma de minimizar os efeitos dessa condição de precarização na qual vivem, as mulheres têm desempenhado papel fundamental na condução de ações que buscam atender às necessidades básicas de consumo das unidades familiares e criar um espaço relativamente favorável de relações sociais na oferta de apoio àquelas reconhecidas como merecedoras do cuidado extra com filhos. No caso das mulheres do Predinho por mim entrevistadas, as narrativas apontavam para formas explícitas de uma dedicação mais declarada para alcançar assistência direta, especialmente no caso daquelas entrevistadas que não contavam efetivamente com a presença de um companheiro provedor e que 
pudesse exercer a função de membro produtivo na família, como também considerou Neves (2014). Há uma valorização interna do trabalho produtivo desempenhado pelas mulheres, mesmo que precarizada e sujeita a menores ganhos. Trabalho e família nesse contexto convergem para uma única esfera de produção e reprodução social desses moradores e, tal como proposto por Moreira e Moser (2017), aponta para um modelo insustentável no qual cabe às mulheres a responsabilidade pelo trabalho produtivo.

Além disso, a valorização do sistema de posições de agentes sociais como decorrentes de situações contextuais, segundo Geertz (2013), chama atenção para a fluidez com que os agentes se estabelecem entre si e com os outros. Nesse sentido, as rearticulações das redes de relações tecidas pelos moradores do Predinho correspondem às possibilidades diferenciadas de conformação de novos campos de ação. No entanto, as distinções internas aos moradores se contrapõem ao modo de vida daqueles que se encontram em condições de completa escassez, tal como é o caso dos moradores do Morro da Providência (local de origem de muitas famílias de moradores do Predinho).

Assim, vivendo na ilegalidade imposta pela impotência do Estado (FASSIN, 1999) em assegurar o direito à moradia, essas famílias constituíram no Predinho um espaço de resistência e de enfrentamento a desfechos institucionais insatisfatórios, tal como observado a partir da delonga processual junto à Defensoria Pública do Estado do Rio de Janeiro. Como parte dessa estrutura de ação possível (ASAD, 1993), os moradores orientam suas ações no sentido de assegurarem a continuidade do projeto de mordia que idealizaram.

Como considerou Lefebvre (2001, p. 13), “[...] os violentos contrastes entre a riqueza e a pobreza, os conflitos entre poderosos e os oprimidos não impedem nem o apego à cidade, nem a contribuição ativa para a beleza da obra". Nesse sentido, esses confrontos corroboram para a valorização do sentimento de pertencimento à cidade, tal como pude observar a partir dos relatos dos moradores.

Apesar de estarem situados na região central do Rio de Janeiro, nas proximidades da Central do Brasil, espaço de confluência de políticas públicas e de canalização de recursos, inclusive de agregação de uma pluralidade de maneiras de viver e ocupar esse espaço, as descontinuidades das relações sociais mais gerais e entre os moradores estabelecem um meio caminho entre aquilo que está na lei e os recursos que podem ser adquiridos a partir de uma ordem próxima de relações. Como busquei demonstrar, os sentidos da luta pela moradia digna se pautam segundo princípios morais e afetivos que orientam fluxos de investimentos na constituição de redes de solidariedade e de afeto pelas mulheres do Predinho. Essas redes de relações operam conforme a condição de vulnerabilidade dessas famílias que resistem, a despeito da política urbanística da capital carioca, na gestão do sofrimento pela permanência na cidade e no atendimento de necessidades básicas da reprodução física e social. 


\section{Referências}

A TRIBUNA. Três hotéis que dão prestígio ao bairro mais badalado do Rio. A 200 metros da praia mais linda, Copacabana, Rio de Janeiro, Seção Anúncios, n. 14985, p. 23, 1999.

ASAD, Talal. Genealogies of Religion: Discipline and Reasons of Power in Christianity and Islam. USA: Johns Hopkins University Press, 1993.

BALANDIER, G. Antropologia Política. São Paulo: Editora da USP, 1969.

BOURDIEU, Pierre. A lógica da prática. In: BOURDIEU, Pierre. O senso prático. 2. ed. Rio de Janeiro: Vozes, 2011. p. 133-163.

DOMINGUES, Michelle Lima. Habitação e comunidade organizada: uma etnografia da mobilização coletiva de famílias trabalhadoras cooperadas em São Gonçalo, RJ. 201 1. 356f. Tese (Doutorado em Antropologia) - PPGA, Universidade Federal Fluminense, Niterói, 2011.

FASSIN, Didier. El hombre sin derechos. Uma figura antropológica de la globalización.

Maguaré, [s.l.], n. 14, p. 179-190, 1999.

FASSIN, Didier. Patetización del mundo. Ensayo de antropología política del sufrimiento. In: VIVEIROS, Mará; GARAY, Gloria (ed.). Cuerpos, diferencias y desigualdades. Bogotá: Universidad Nacional de Colombia, 1999. p. 31-41.

FURNO, Juliane da Costa. O Trabalho das Mulheres: entre a produção e a reprodução social. Campinas, SP: [s.n.], 2015. p. 1-9.

GEERTZ, C. O Saber Local: Novos Ensaios em Antropologia Interpretativa. 13. ed. Petrópolis: Vozes, 2013. p. 169-238.

JORNAL DO BRASIL. Hotel Bandeirantes, Rio de Janeiro, Seção Notícias, n. 292, p. 42, 1988.

LEEDS, A.; LEEDS, E. A Sociología do Brasil Urbano. 2. ed. Rio de Janeiro: Faperj; Fiocruz, 2015.

LEFEBVRE, Henri. O direito à cidade. São Paulo: Centauro, 2001 .

MALINOWSKI, Bronislaw. Argonautas do Pacífico Ocidental. São Paulo: Abril Cultural, 1998.

MORAES, A. Experimentações baldias \& paixões de retomada. Vida e luta na cidadeacampamento. 2020. 440f. Tese (Doutorado em Antropologia Social] - Programa de PósGraduação em Antropologia Social, Universidade Federal do Rio de Janeiro, Rio de Janeiro, 2020.

MOREIRA, T. A.; MOSER, L. O conflito entre trabalho e vida familiar no contexto da produção e reprodução social capitalista. In: II SEMINÁRIO NACIONAL DE SERVIÇO SOCIAL, TRABALHO E POLÍTICAS SOCIAIS. Florianópolis, 2017. Anais [...]. Florianópolis, 2017.

NEVES, D. P. Habitantes de rua e vicissitudes do trabalhador livre. Antropolítica, [s.l.], n. 29, p. 99-130, 2011.

NEVES, D. P. Mulheres e mercado de trabalho: afiliações e conquistas. Niterói: Alternativa, 2014.

PATERNIANI, S. Z. Movimento é movimento, governo é governo? A luta por moradia e a política habitacional em São Paulo. In: IV COLÓQUIO INTERNACIONAL DE DOUTORANDOS DO CES. São Paulo, 2013. Anais [...]. 2013.

PIRES, L. Esculhamba, mas não esculacha! Niterói: EdUFF, 2011. 
SANTOS, P.T. dos. Campos de ação de agricultores de Vargem Grande, Teresópolis (RJ): princípios de afiliação e redes de interseção. 2015. 259f. Tese (Doutorado em Antropologia) - Programa de Pós-Graduação em Antropologia, Universidade Federal Fluminense, Niterói, 2015.

SARTI, C. A. A família como espelho: um estudo sobre a moral dos pobres. São Paulo: Autores Associados, 1996.

WEBER, M. A ética protestante e o espírito do capitalismo. São Paulo: Martin Claret, 2001.

\section{Priscila Tavares dos Santos}

Pós-doutoranda em Antropologia pelo Programa de Pós-Graduação em Antropologia da Universidade Federal Fluminense, Niterói, Rio de Janeiro, Brasil. Expert consultant na Maxwell School of Citizenship \& Public Affairs, Syracuse University, desde 2017, no projeto de pesquisa intitulado Helping the Poor Stay Put: Affordable Housing and Non-Peripheralization in Rio de Janeiro, Brazil. Pesquisadora associada do Instituto de Estudos Avançados em Administração de Conflitos (INCT/InEAC/UFF). Mestre e Doutora em Antropologia pelo Programa de Pós-Graduação em Antropologia da Universidade Federal Fluminense.

Endereço profissional: Programa de Pós-Graduação em Antropologia da Universidade Federal Fluminense, Campus do Gragoatá, Bloco O, $3^{\circ}$ andar, Niterói, Rio de Janeiro. CEP: 24220-900.

E-mail:pris_tavares2000@yahoo.com.br

ORCID: https://orcid.org/0000-0002-8189-539X

\section{Como referenciar este artigo:}

SANTOS, Priscila Tavares dos. Gestão do Sofrimento e Luta pela Moradia por Famílias Trabalhadoras. Ilha - Revista de Antropologia, Florianópolis, v. 23, n. 3, p. 6-20, setembro de 2021. 